NB: This paper is a pre-publication version that appears in lieu of the publisher's own version of record.

\title{
Running with the ball? Making a play for sport heritage archives in Higher Education contexts
}

\begin{abstract}
For considerable time, academia (in particular, the Humanities) has been in an intellectual, economic and pragmatic par des deux with the culture and arts sector (in this case, heritage, museums and archives). In many ways, given their respective pursuits of scientific enquiry and learning, valuable contribution to a knowledge economy, commitment to public enlightenment, and exploration of critical and creative endeavour, a relationship between the sectors makes sense. Unity notwithstanding, the relationships have become increasingly now influenced by (en)forced contextual constraints (e.g., government policy development and intervention, neoliberal market forces, structural and ideological shifts in funding acquisition and allocation, patronage changes and demands, and/or individual political priorities) (Dubuc 2011; McCall and Gray 2014; Watson 2002). Drawing on education and heritage scholarship, and theoretical frameworks of sport culture spaces (Hardy, Loy and Booth 2009; Phillips 2012; Pinson 2017), this paper examines efforts undertaken at one specific Higher Education establishment in the United Kingdom in which institutional agendas (vis-à-vis historical and cultural foci, encouraging 'impactful' academic activity, brand exposure, economic efficiency, and community engagement) have contoured, and become entwined with, an embryonic sport heritage and archive project. Recalling similar arrangements elsewhere (Krüger 2014; Reilly, Clayton and Hughson 2014; Reilly 2015), the aim of this case study is to explore how the wider education and cultural policy context have precipitated an increasingly symbiotic and dependent relationship between university and cultural/arts initiatives. The paper considers how the impetus to develop a sports-based (basketball) heritage archive and study centre reflects the current fragilities of the two sectors, yet, concomitantly, reveals the potentials that might be developed from fostering greater intellectual and pragmatic alliances. The paper concludes by advocating the practical, political and ideological usefulness of network formation, sustainability measures and continued cross-sector dialogue.
\end{abstract}

\section{Key words}

Higher Education, heritage, archive, sport history, basketball 


\section{Running with the ball? Making a play for sport heritage archives in Higher Education contexts}

\section{Introduction}

Recent scholarly, public and political debate has signalled trying times for Higher Education in and beyond the United Kingdom (Bennworth and Jongbloed 2010; Giroux 2014; Watson 2002). Discussions have identified numerous forces that have precipitated shifts in the identities, functions and civic value of Higher Education institutions. Forces have included, for example, increased market competition, state funding and support changes, global economic perturbations, demographic shifts, internationalisation of the labour force, the introduction and development of performance-based research and teaching frameworks, pre- and post-European Union ('Brexit') impacts, and consumer and industry-driven alterations underscored by graduate 'employability' imperatives (Brown and Carasso 2013; Riddell Weedon and Minty 2015). These forces have challenged Higher Education providers to continually rationalise their existence and secure longer- term sustainability and profitability. Such challenges underscore fundamental shifts in how Higher Education entities are understood as industrial enterprises operating within the context of a competitive marketplace. Even cursory overviews of the some of the publicly available data (e.g. strategic plans, financial reports, Research and Teaching Excellence Framework materials, Higher Education and mainstream media reports) evidence the difficult context in which United Kingdom universities are existing and the extensive efforts being made to ensure academia continues to work in meaningful and effective ways. To this end, and although a feature of previous Higher Education eras, the ability of universities to build and strengthen their profile by developing productive synergies and relationships with an increasingly wider remit of industries and sectors beyond the Tertiary context remains of value.

That universities forge 'productive relationships' with other areas of society is not particularly profound. Higher Education providers (in and beyond the United Kingdom) appear to share at their core some notion of commitment to fostering partnerships beyond their campuses and making 'real-world' 'impacts' that resonate with local, regional and/or global communities (Paradeise et al. 2009; Riddell, Weedon and Minty 2015; Watson 2002). Though such goals may fill the aspirational agendas of universities, within the United Kingdom recent government demands and policy mandates have crystallized the necessity of Tertiary industry intersectionality and made external relationship crafting central to funding and development maxims (Boys, Boddington and Speight 2016; Brown and Carasso 2013). Whether explicitly informed and stressed by the State, or borne of other factors, universities have had to become increasingly savvy in turning strategic partnerships to their causes. One example of intersection has been some universities' relationships with the culture and arts sector (or more specifically, heritage, museums and archives) (Boys, Boddington and Speight 2016; Janes 2009). However, as scholars such as Pinson (2017) and Krüger (2014) have noted, as is explored below, in some cases there appears to be a reluctance within corners of the contemporary Tertiary sector to readily embrace archival/heritage investment. These concerns are evidently intertwined with underpinning ideological and political debates that have contributed to tiered (and often implicit) evaluation of different forms of heritage. The crux of evaluation relies on not what heritage 
matters per se, rather on what heritage matters more. Notwithstanding a vibrant international, national and local heritage scene, and as is demonstrated in the discussion below, sport heritage has not always fared well in jostling for its position in this game.

Utilising one specific sport heritage and archive project as a case study, this paper takes some of issues that have shaped the Higher Education and culture arts sector intersections as its focus. The paper considers the establishment of NBHASC with the aim of understanding how political and cultural forces may precipitate and contour contemporary relationships between university and cultural/arts sectors. I begin by articulating some of the broader landscape changes affecting higher education and cultural and arts sectors. I then examine university and sport heritage connections to raise wider debate over industry intersectionality. I follow by articulating the genesis and evolution of the National Basketball Heritage Archive and Study Centre (NBHASC) as an exemplar of some of the potentialities and difficulties inherent in university's heritage work. I then discuss how some of the current heritage woes might be addressed and opportunities for growth and sustainability could be explored.

\section{Industry change and collaboration calls}

Although contextually-driven introspection, identity malaise and ideological, managerial and operational shifts affect other sectors of the economy, culture and arts scholars have articulated specific concerns with respect to the industry's political pressures, financial issues, pedagogical functions, broadened community engagement, and reorientation (Boys Boddington and Speight2016; Dubuc 2011; Déom 2008; Janes 2009; McCall and Gray, 2014). Recent changes have entailed moves to better align the industry with current economic climes and commercial influences, consumer reorientations, state and civic rationales vis-àvis scientific inquiry, cultural symbolism, and education and entertainment (Dubuc 2011). Examining the North American museum and heritage context, Dubuc (2011) notes that the sector is witnessing a process of 'profound transformation' that has generated concern about what culture and arts industries do, who they speak for, and who they might need to work with to better 'speak to' the communities they seek to represent. These redirections in museum and curatorial practice often have strong economic undertones; namely, by being closely aligned with central or local government or sponsors performance-based funding criteria and or accountability and management imperatives that demand measurable outcomes that can be used to substantiate investment value and legitimise sector activity (Bewley and Maaer 2014; Janes 2009; McCall and Gray, 2014).

Whether economic undertones of the context are favourable or not, the heritage and museum sector must continue trying to work effectively and efficiently. To do so, Dubuc (2011) advocates strengthening collaborations with academia. Both academia and the culture and arts sector share, Dubuc (2011) acknowledges, an interest in advancing civic enlightenment, shaping social consciousness, and encouraging global reflection and critique. In the broadest sense, a collective commitment to public pedagogy sits central to the agendas and activities of Higher Education and the culture and arts sectors. Examples include Heritage England's ongoing work with a number of UK universities on projects of national public, social and cultural significance, and their support of Doctorial Training Partnerships; the renowned Collaborative for Cultural Heritage Management and Policy located at the University of Illinois involving multilateral international University and industry networks; and, USA-based non-profit organisation Global Heritage Fund working in 
concert with academics on preservation and cultural protection projects, largely in war-torn and political conflict regions. Other examples, too, point to productive alignment. Documenting a successful initiative at the University of Montreal, Déom (2008) has noted the multifarious value of collaboration to the respective and shared identities, public missions and political advocacy of both project participants and cross-industry relationships. Unity in principle and practice, in this case, provided a means to raise awareness about cultural preservation, demonstrate the utility of research-informed civic policy and decisionmaking, showcase the benefits of co-supporting training and educational placements, and mobilise community and business interest. Such approaches attest to some of the benefits of strong cross-sector collaboration and commitment to sustainable, practical, project development.

Many initiatives within the heritage and museum sector have benefitted from alliances with universities (Boys, Boddington and Speight2016; Dubuc 2011). Partnerships with universities help in providing the sector with professional, practical and/or managerial advice, adding scholarly insight and research rigor, enhancing creativity, widening participation and communication, offering financial support, and adding political and ideological weight to the legitimacy of the sector's activities. In turn, universities appear to have appreciated the sector's various utility to act as a vibrant context and outlet for research and teaching activities; a way to evidence meaningful community engagement; demonstrate patronage, philanthropy and corporate social responsibility; and, build interest and support for their mutual causes (Boys, Boddington and Speight2016). Fruitful outcomes aside, some criticism has been made of the need for synergy and the consequences that encouraging stronger intersections may have (Haxthausen 2001; Mason 2006). The relationships have not always been harmonious or mutually-advantageous, but rather, in some cases, troubled by instability, inequity, and ambiguity (Boys, Boddington and Speight 2016; Haxthausen 2001; Janes 2009; Johnes 2013; Teather 1991).

Regardless of focus or context, difficulties advocating for intersectional heritage projects are not particularly helped by the conceptual, ideological, pragmatic and semantic definitions and uses of the term which have, invariably, muddied inter-disciplinary dialogue, political debate and progress. Conceptualised, variously, as 'experience', 'identity', 'performance', 'tangible and intangible', 'authorized/unauthorized', various scholars and many contributors to this journal already note that 'heritage' is multifaceted, complex, and politically, culturally and ideologically-laden term (Ahmed 2006; Harvey 2001; Mydland and Grahn 2012; Robertson 2016; Smith 2006; Waterton and Watson 2015). The (often contrasting and contradictory) configurations of heritage articulated within research, policy spaces and industry practices have opened discussion about its significance and wider value(s). Yet, its varied use has also presented challenges to those aiming to advance its causes within the culture and arts sector and across other spaces (Robertson 2016; Waterton and Watson 2015). These considerations are significant in the context of this paper in demonstrating that if interpretations and understandings of heritage differ within and among stakeholders this may have implications for effective cross-sector endeavour. In terms of this research, for example, tensions around heritage meaning and making among varied stakeholders of the country's basketball communities has, invariably, consequences for fostering constructive dialogue and productive enterprise; establishing project foci, priorities and objectives; developing effective governance, accountability and representation; deciding 
appropriate economic investment and sustainability measures; and determining evaluation mechanisms.

Heritage debates withstanding, this paper focuses on the establishment of a specific collection as one element of historically orientated practices within sport. In doing so, and rehearsing the contemporary conceptualisations of heritage as a 'process' (Smith 2006; Harvey 2001), the emphasis in this research has been placed on an interrogation of the National Basketball Heritage Archive and Study Centre (NBHASC) collection - discussed below - as a 'product' of wider heritage practices within the sport. Such a positioning requires a necessary acknowledgement of the inherent intangible nature of the sports heritage; to recall the sentiments of Smith (2006), that which recognises that basketball social and cultural sites and objects do not, on their own carry an inherent meaning. Rather, meaning is ascribed as part of continuous planned and unplanned heritage practices. Essentially, the NBHASC collection may be considered a distinct heritage object, yet its 'value' does not immediately derive from its material existence. Instead, value is ascribed via managerial and curatorial practices that craft, cultivate and contextualise (particular) interpretations of the sport, and, are influenced by the dynamic cultural contexts and ideological systems within which these articulations reside. Old basketball videos or photographs (such as those currently found within the NBHASC) may be interesting artefacts, though without sufficient curatorial processes to situate these within broader temporal-geographic-spatial-political narratives of the sport their meaning and cultural significance remain moot. Current heritage discourse is, therefore, useful in establishing cautionary caveats toward the configuration of the entities such as NBHASC as innately heritage and their potential security and value within and beyond institutional settings.

\section{University and Sport Heritage intersections}

The development of sport heritage archives has gained substantial academic, social, cultural and commercial prominence in recent decades as sport organisations work to not only preserve and consolidate a sense of historical permanence but, also, provide outlets and engagement opportunities that satisfy public and corporate interests (Reilly 2014; Reilly, Clayton and Hughson 2014; Moore 1997; 2013; Phillips 2008; Vamplew 2004; Wood 2005). Concomitantly, given a climate of financial competitiveness and uncertainty, sport organisations are turning to academic institutions to enhance the credibility, value and knowledge transfer potential of their respective histories and heritage projects. Conversely, within Higher Education, academics remain steadfast in their reliance on sport heritage archives to articulate narratives about the past and to better understand the politicisation of historical content in the present. For researchers, sport organisations, the public, educators, students and the media, sport heritage archives are a key space in which questions of global, national and collective identity, belonging and 'common' cultural can be examined. Yet, as encouraging as calls within academe and from the wider culture and arts spectrum toward greater collaboration, and advances made by some universities (discussed further on), have been, there has been some trepidation within the sport studies realms of Higher Education to work more closely (Hill, Moore and Wood 2012; Johnes 2013; Johnes and Mason, 2003).

Critique of the intersectionality between sport academe and sports' cultural, heritage and museum spaces has been a notable feature of scholarly debates in in recent times. A key focus has been to foster critical discourse of sports' histories cultural production and 
consumption, and articulate the socio-cultural, political and economic value of preserving, celebrating and disseminating the sporting past as cultural heritage. The museum and heritage sector, Johnes (2013) notes, has become particularly sophisticated in its aims and intentions; part of which, in response to economic, political and cultural forces and challenges, has been the need to seek out and maintain alliances with academe. While some sport scholars may have affectations and an appreciation of museum and heritage contexts, collective efforts to forge and sustain closer ties to the sector have garnered mixed support (Hill, Moore and Wood 2012; Reilly, Clayton and Hughson 2014). Notwithstanding some individual and/or institutional efforts (such as the National Football Museum's connection to the International Football Institute based at the University of Central Lancashire which has successfully led to Arts and Humanities Research Council funding and doctoral opportunities), Johnes (2013) laments that sports studies academics have not worked as hard as they could do to forge closer relations with the museum and heritage sector.

The early work of Snyder (1991), Kidd (1996) Vamplew (1998), and to a lesser extent Bouchier and Cruickshank (1998) and Crawford (1996), was effective in establishing dialogue about popular sport history and heritage practices, ideological and politicised roles of hegemony and nostalgia in production and consumption processes, and the inherent intersectionality of sport heritage with State, economic, cultural and policy domains. These examinations were furthered by contemporary scholars from a variety of sport subdisciplinary perspectives; notably within History (Booth 2012; Borish and Phillips 2012; Huggins 2012; Kohe 2010; Osmond and Phillips, 2011; Phillips 2012), but also Sociology (Stride, Wilson and Thomas 2013), Tourism (Ritchie and Adair, 2004), Management (Pfleegor and Seifried 2012; Friedman 2007), Physical Education (Phillips and Tinning 2011), Coaching (Day, Carter and Carpenter, 2013) and Disability studies (Brittain, Ramshaw and Gammon 2013), as well as more generally within Heritage, Tourism and Museum research (Fairly and Gammon 2005; Gammon and Ramshaw 2007; Pinson 2017). This research has collectively argued for sport heritage's value as a significant and substantive cultural product; the democratisation of sport heritage spaces; improved recognition, advocacy and representation of the marginalised and disenfranchised 'other'; and, the engendering of greater critical rigor in public heritage processes and performances.

Of most use has been initial work of Hardy, Loy and Booth (2009), and the recent additions of Murray Phillips (2012) and Pinson (2017) to provide conceptual frameworks, typologies and theoretical configurations of sports' material cultures and heritage foci. Synthesising current debates, Phillips' (2012) work advances needed critique of the (often sacrosanct) status, roles, intention, politicised production and consumption, and critique of historical artefacts and/or their contexts. Primarily focusing on sport museums, Phillips' typology $(2012,6)$ is of value is evaluating the landscape of sport heritage contexts/types, knowledge bases, governance and economic underpinnings. Phillips specifically articulates four key exhibition types (Academic, Corporate, Community, Vernacular). Each type draws on different information repositories (e.g., from scholarly, market research, oral tradition, experiential and popular culture), and receives distinct funding streams, to 'frame'/produce sport heritage in specific ways for consumer audiences. Though cogniscent of typology limitations (for example, in not easily accounting for the complexities and hybridity of heritage and museum forms, or inherent sector intersectionality in some cases), Phillips' general model highlights key distinctions in practices, and how particular forces and stakeholder interests can be identified and understood within and across heritage spaces. 
On an initial assessment, the development of a civic and Higher Education-based national basketball heritage project like the NBHASC aligns with the typology's academic and community exhibition types, resourcing by scholarly, oral and popular culture knowledge, and initiatives that are financially supported the public purse. Yet, as the case study explored in this paper details, the typological classification and developmental story of this specific national sport heritage site is not so straightforward.

Most currently, Pinson's (2017) examination establishes distinct intersectionality between the sustainability of national sport events and their recognition as a heritage good. Pinson's case for the value of Heritage Sport Events (HSE), and by default the call for industry sectors to work more cohesively for mutual benefit, is useful in considering how sport heritage, higher education and cultural/arts realms might work in synergy, and democratically, to advance collective causes. Pinson's conceptualisation of the process that turns HSEs into 'territorial resources' $(2017,138)$ aids arguments advanced in this paper about the value of investments into national basketball heritage to the local supporter communities, University, city and sport governing body (to be discussed later). Taken in totality, this work provides instrumental interrogation of the industry and scholarly efforts to engage and bridge the public/popular-academia divide.

The potentialities and frustrations of encouraging more productive intersections between sport academia and museums and heritage spaces has also been experienced and articulated elsewhere. Outlining the situation in Germany, Krüger (2014) notes that although strong traditions and cultures of remembrance and tradition exist within the country's sport culture, it has taken some time to develop fertile ground upon which academic and cultural sector hybridity might germinated. Museum and heritage-based sport industries may comprise a relatively small dimension of the country's cultural sector, Krüger (2014) suggests, but they are bolstered and sustained by dedicated contingent of local, regional and nationally-minded individuals and groups. In the past decade or so, the museum, heritage and archival work of these sport enthusiasts has been met by academic communities of interest who have provided professional support; namely by improving access, dissemination and outreach, helping advance mutual causes and assisting political advocacy. Academics have been, for instance, integral in establishing of the non-profit Deutsche Arbeitsgemeinschaft von Sportmuseen, Sportarchiven und Sportsammlungen (DAGS). Similar to the formation of the Sport Heritage and Sport in Museums Networks in the United Kingdom (see Reilly, 2014; Reilly, Clayton and Hughson 2014), the non-profit entity was founded to provide a practical and ideological 'home' for the disparate and fragmented domestic array of sport historical and heritage initiatives. For Krüger the rationale for facilitating long-term collaborative work is simple; "these sport historical museums, archives, documents centres and collections", he writes, "need professional support" (2014, 1430-1431). Underlying Krüger's observations is a general sentiment that irrespective of any explicit institutionally proscribed intentions, (sport) academia should, invariably, acknowledge a moral obligation and duty of care to support domestic heritage activities as best they can.

Although initiatives represented on the United States-based H-Sport archive project point to constructive points of alliance (see, https://networks.h-net.org/node/2622/pages/3483/hsport-archive-project), Reilly (2015) has additionally noted that the growth of academic sport history has not been matched with sufficient engagement, support and integrated work with the sport heritage (and specifically museum) sector. While reasserting the varied 
and valued cultural, political and social significance of sport-related museum and heritage spaces (Hill, Moore and Wood 2012; Moore 1997; 2013; Phillips 2012; Vamplew 2004), scholarship has yet to make a profound case for collaborative endeavour. Both academia and the cultural sector, Reilly (2015), Reilly, Clayton and Hughson (2014) and Moore (2013) remark, share an affinity and respect for sports' histories, though appear to differ occasionally with respect to criticality, politicisation and contextualisation of content, modes of (re)presentation and performance, and consumer orientations. Such differences (whether real or perceived) have generated scepticism among some within each respective industry that has seemingly worked against advancing more productive relations.

Heritage issues - in particular, the need to advance scholarly examination to add value to and legitimise heritage practices - have also been documented in other sport domains. In their extensive examination of Olympic stadia sites as heritage monuments, for example, Kiuri and Teller (2015) make an empirical case for furthering sport heritage research. Focusing on the built environment, Kiuri and Teller stress the significance of undertaking more activities to recognise, preserve and promote sites of international, regional and/or local historical significance. The issues colleagues have collectively outlined above suggests that the development and sustainability of the sport heritage/museum industry requires the combined attention, energy and investment from culture and academic sectors. These debates are useful to cogitate upon in the proceeding sections of the paper.

\section{Basketball history, heritage hoops \& the NBHASC}

Having been played in the UK for at least the last 120 years, basketball has developed a relatively popular following, competitive league structure, and domestic/national management via English Basketball Association and British Basketball League. Progression and administration of the game has not, to note, been concomitant with consistent commitments to the sport's heritage. In the first instance, ad hoc development and laboured efforts to establish a national sport federation (which did not happen until the 1930s) (Myerscough 1993; Mandel 2015), appear to have inhibited the systematic and strategic collection of an administrative (let alone broader heritage) repository. Although there have been marginal academic efforts made to articulate the sport's histories and (g)localised developments in more recent times (e.g., Falcous and Maguire 2005; Faulkner 2017; Maguire 1994; Mandel 2015; Myerscough 1993), heritage work has largely been benched. Existing research, and administrative documents of the national British Basketball Association, aside, scholars' abilities to alter basketball's liminal position as content matter within academe has been constrained; namely, by the ad-hoc and amateur nature of its early administrators and also constituents of the sport who been fragmented and peripatetic in gathering, preserving, documenting the sports' cultural, social and material fabric.

From the 1980s onwards, and spurned on by the American-led globalisation of the sport writ large which drove player-labour migration, intensified consumption practices, and crystalized commercial imperatives, the sport experienced considerable growth (Maguire 1994; Falcous and Maguire, 2005). Change facilitated fan engagement with the sport and strengthened notions of an identifiable basketball 'community', however it did little to advance heritage related activities and interest beyond the level of individual enthusiasts. 
These individuals, often coaches, administrators and/or fans, attempted to disseminate narratives about the sport (for example, occasional programmes, promotional booklets, or coaching/education resources) to showcase the sport's broader history and key agents of the game in Britain.

In the case of basketball, financial, organisational and political forces appear to have been prohibitive to heritage projects. The continued progression of the professional game in the last decade or so, for example, has brought new economic streams to the sport (largely via sponsorship, television rights and merchandising), yet, at all levels funding precarities remain (Sheen 2016). The situation in basketball is, invariably, echoed in many other marginal sports whereby economic constraints necessitate pragmatic decisions that must be made in terms of areas of investment and focus. Nonetheless, one ramification has been the lack of favourable conditions for heritage investment. Added to the paucity of economic resources are the differences in organisational and political imperatives and agendas of groups and individuals within the sport. The national governing body, professional league organisation, affiliated teams within the competitive leagues, stakeholders and owners, and the European and international federation all, variously, contribute to how the game is organised and managed, but do not always share the same vision for the sport, its future or, in this case, preserving and celebrating its pasts. Political differences, conflicts and negotiations may be an inherent and understandable feature of organisational interactions (including those within the museum sector) (Boys, Boddington and Speight. 2016; Janes 2009), yet in the context of this paper the point is that the marginal nature of the sport, economic pressures, multiple stakeholder landscape, individual ideological differences among members, lack of distinct recognition within national and domestic levels of the organisation with regards to the sport's history, all conspire against a shared commitment and investment into heritage practice.

Most recently, the drive for heritage recognition has come from individuals within the basketball community. Like other sports, basketball in the United Kingdom has its aficionados whose innate love of the game, nostalgia for their involvement as players, coaches or fans, dedicated collector hobby-ism, and emotional desire to share experiences, push heritage advocacy. It was among these enthusiasts that the genesis of a specific national heritage project took root. Reflecting their long-standing patronage to the sport, some individuals had amassed significant, and deeply personal, collections of basketball related material (e.g., books, magazines, videos and DVDS, photographs and posters, pressclippings, match booklets and statistical reports, official documents, education resources, trophies, and clothing). One such individual was former player, official statistician, and passionate fan, John Atkinson. Independent of Myserscough (1997) and Mandel (2015), Atkinson's role and prominence as a respected figure within the national game made him well placed to try to advance the needed support for heritage investment. Yet, for some of the reasons identified above and others unknown, Atkinson's efforts for national organisational support failed to materialise.

Interest from the national federation may not have been forthcoming, but Atkinson courted other parties; including the University of Worcester. The choice of University was no coincidence. Over approximately the past 17 years the University has made a significant name for itself as a, if not the, hub for basketball in the country. Although the city's team, the Worcester Wolves ${ }^{\mathrm{TM}}$ (which is supported by the University), was a relative late-comer to the British Basketball League, the team has had considerable success; regularly remaining in 
upper-most echelons of the league. With high calibre players, well-attended weekly fixtures, the University and city co-hosting the European Wheelchair Basketball Championships in 2015, a Master's programme in basketball coaching science, strong partnerships with European basketball centres and universities, the status and support for basketball within the city is substantial. The local strength of basketball culture, and the University's commitment to developing the game, was also recognised by the European Basketball Federation (FIBA Europe) officially endorsing the university as an International Centre for Basketball Research. The context provided fertile grounds for a national heritage project.

Notwithstanding positive discussions and sentiments, and despite the University's broader strategic commitment to heritage and culture (University of Worcester 2013), it took until mid-2015 before an agreement about the collection was reached. Part of the hesitation being the logistics of space and pragmatics of management. The university already had large archival collections and historical materials spread across its campuses but was significantly pressed for space. In 2013, however, the university and city had opened a new combined library and local services building (named 'The Hive') that had more space, housed the regional county council archives, and had national archive standard accreditation. The Hive presented an opportunity for the university to better address its commitments to sport, heritage and culture, civic service and engagement.

To mark my involvement, I arrived into the project in mid-2015. As an academic Sport Historian, I accepted the invitation to work on the initial development and direct the public engagement activities. Our initial collective of interested parties also included two more of Atkinson's basketball peers, plus the University's Research Collections and Archive Officer, and representatives from the university library services. The initial discussion was productive, though mainly focused on facilitating the donation of Atkinson's collection, broader acquisition management, garnering further University and basketball industry support, and encouraging wider dissemination and public use. Early on the decision was made to use the collection as the base for a domestic repository and 'centre' for the sport's heritage; which thus became, the National Basketball Heritage Archive and Study Centre (NBHASC).

In addition to establishing a notional home for incoming collections, the intention was to provide an ideological and physical space to showcase the sport's cultural and social histories, and related contribution to the United Kingdom's broader sporting traditions. Information about the establishment of the NBHASC was disseminated among the basketball community so that interested individuals could understand the significance and utility of the materials we were keen to collect. The NBHASC launch coincided with the National Sport Heritage Day on $26^{\text {th }}$ September 2016 (though activities go on around the United Kingdom over the course of the week and month, the day is designed as a flagship community engagement and outreach initiative of the newly formed Sport in Museums network (formerly the Sport Heritage Network), see http://www.sportinmuseums.org.uk/). Further to the sustained work the Network does to support clubs, groups, schools and individuals with sport-heritage development (Reilly 2015; Reilly, Clayton and Hughson 2014), the flurry of activities around Sport Heritage Day attract significant media, public and social media attention.

The launch included various presentations on the university's tradition in academic sport history, the early history of basketball in England, basketball labour migration, and an 
overview of the archive collection. In addition, the event was promoted extensively on social media, local and regional media outlets, and on the heavily frequented national basketball news forum Hoopsfix (see http://www.hoopsfix.com/2016/10/launch-of-thenational-basketball-heritage-archive-and-studies-centre/). The NBHASC also benefited from employing a paid student-intern who was instrumental in mapping, documenting and organising the existing collection, identifying substantial research themes, digitisation of materials, public exhibit development, facilitating the construction of the NBHASC's web interfaces, and the production of an embryonic online resource to enhance public engagement. The culmination of these activities was also the establishment of two distinct online spaces that provide a useful means to highlight the centre's varied contents and attract wider public patronage. The spaces:

http://www.nationalsportsmuseumonline.org.uk/content/collection/university-worcesterresearch-collections-basketball-heritage-collection and,

http://library.worc.ac.uk/research-collections/basketball-heritage

contain key information about the centre and include contact details for those interested in supporting or using the archive collection.

Noting similar archives established elsewhere (notably within U.S.A university settings), there is confidence (tempered with trepidation) that the NBHASC will provide opportunities to inform understandings of basketball and cultural meaning-making within the United Kingdom. While the NBHASC remains committed to growing and providing a safe home for the collection, enabling heritage networking, presenting and educating people about the sport, and more broadly aiding the university's commitments to student employability, work remains. The project is currently managed by just two project members on an informal basis. Congruent with other sport heritage spaces (Reilly 2015; Reilly, Clayton and Hughson 2014), with limited human resources there is an ongoing need to continue assessing the breadth and depth of the archives content, examine the extent of key pieces therein, and consider ways the material may be best utilised, showcased, disseminated or made available to the widest possible audience. Yet, initial work to get the NBHASC off the bench and onto the heritage court has led to some discernible outcomes and keen interest among the basketball and academic sport history community. Such signs are promising for the centre to be developed as a valuable, substantial and unique research and educational resource.

\section{Higher education woes and the consequence for heritage projects}

The NBHASC case study raises several points with respect to intersections of heritage and archive management and higher education. In the immediate sense, the NBHASC is relatively new. Its development and initial activities have been successful (at least a far as the project team are concerned), and several early-stage goals have been met. Part of this is due to NBHASC coming under the auspices of the university's library services and research collections division. As such, the centre does not currently have (nor necessarily require) its own, distinct, funding stream for survival. Akin to collections and initiatives elsewhere that encapsulate sport culture preservation within tertiary infrastructures (see, for example, Reilly 2015; Reilly, Clayton and Hughson 2014), university integration affords the collection a degree of physical security and a direct connection to the research community and sporting community. Given university strategies to prioritise heritage and culture, and support 
sporting activities, the founding of the NBHASC is a 'good fit' and makes considerable sense. Moreover, following the trend set by the university's existing archive collections (for example, on children's literature, poetry, and fashion), the NBHASC's intentions are congruent with the institution's agendas (vis-à-vis historical and cultural foci, encouraging 'impactful' academic activity, brand exposure, economic efficiency, and community engagement). Rehearsing concerns expressed earlier, it is evident that while the university may have eventually embraced the NBHASC, the centre's existence is still dependent on favourable institutional and Tertiary sector conditions; which, in neoliberal climes, have made the process of justifying 'economic', 'impact' and 'public' utility a core function. A geographic and political 'fit' for the NBHASC may currently create an amiable context, yet offer only limited guarantee for continuity.

Current arrangements offer the NBHASC some comfort. Yet, the university has other priorities that temper its financial and practical commitments to the centre's development. While library and service budgets may cover investments into archive collections, any funding is ultimately tied to the university's wider financial position, strategic plan, research and teaching orientation and capital development imperatives (Paradeise et al. 2009). These are inherently coupled to student recruitment numbers and associated revenue from student fees; which at present, due to a demographic trend in the UK, are at historic lows (see HESA, 2017). Concerns over student numbers and fees, and the competitive Higher Education market, do and will persist, and universities will do what they can to remain viable and attractive. One counterpoint, however, are the funding streams that have originated from the most recent round of the Research Excellent Framework (REF) exercise. Notwithstanding its comparatively small, yet still substantive, submission for REF 2014, the university received funds that it could turn to fulfil its strategic goals in research, teaching and community engagement. Part of these funds have been used to support a growing number of fully-funded PhD schemes, open-access publication, vacation research assistantships (including that used to start the NBHASC) and staff research leave schemes.

In advancing a rationale for basketball heritage investment, here it is valuable to rehearse Pinson's (2017) argument regarding Heritage Sport Events as territorial resources. Even in its nascent stage, and although not an event per se, the NBHASC has gained recognition among the sport's fraternity and, by the nature of its University and civic location, resides in a context that aids its profile, development and sustainability. Some economic forces and events outlined above bode well for the nascent NBHASC, particularly in terms of enabling research dissemination initiatives and future collection management and public outreach work. Yet, while the NBHASC may be underpinned by and bear some of the hallmarks of Pinson's HSE framework (e.g., symbols, a narrative, local governance and recurrence), and a favourable environment, the landscape upon which the NBHASC might grow is still rough and its stability as a territorial resource is not yet guaranteed. Within the university funding system, however, application for some of the above schemes requires an existing evidence base of research, discernible 'outcomes', and/or a rationale distinctly mapped to the university's stated mission. For a new centre without yet a reputation, and for a sport in which historical research is considerably lacking, this is a difficult task. Hence a desire to find alternative ways and means to build NBHASC.

Toward this aim, several grant schemes such as those offered by the National Heritage Lotteries, the Arts and Humanities Research Council, and the Economic and Social Research Council might provide financial and pragmatic platforms upon which to develop the centre. 
At a time in which universities require/pressure/demand/encourage employees to justify internal research activities, and must demonstrate their own (self-)sufficiency, these schemes have become increasingly valuable measures of the legitimacy, value and 'impact' of scholarly and community endeavour (Benneworth and Jongbloed 2010; Giroux 2014; Watson 2002). Respecting the precarity of the culture and arts sector (and the museum and heritage aspects therein) and those within academia whose research depends on these industries, the pursuit of such grants (as a way of building and sustaining valued, and legitimate, cross-sector partnership) may be considered important. Yet, as noted by others working across tertiary-arts intersections, pursuit of grant awards or sponsorship can be highly competitive, resource intensive, time sensitive, and laboured with uncertainty; all which may bear heavily on the ability of projects to become established, be sustainable and, eventually, successful (Benneworth and Jongbloed, 2010). To note, however, even when financial investment can be secured, there may be expectations and obligation levied on the heritage site. As Phillips' (2012) typology helps indicate, and the considerable work of colleagues has evidenced, whether charitable benefactor, corporate sponsor, State or nongovernmental organisation, all have the potential to exert influence on heritage practice, development, governance, and the politicisation of content and narrative.

The point here is not to lament the financial difficulties that contour the sectors and may impinge upon the effectiveness of heritage projects such as the NBHASC. These considerations are not new to workers in the wider humanities and arts industries, or those focused on museum and heritage spaces. Money may matter in terms of what might be able to be achieved within the context of heritage projects, yet financial viability and economic value are not the only measures by which the legitimacy of such projects should be considered (Clark 2006; Clark and Maeer 2008). Moreover, there is sufficient evidence to suggest the ability of these areas to forge productive and positive dialogue and activity irrespective of economic forces and/or constraints (Déom 2008; Haxthausen 2001). That many initiatives rely on limited human and financial resources, depend heavily on volunteer and/or community labour, ad-hoc philanthropy, generously offered academic consultation and research support (Dubuc 2011; Janes 2009; Teather 1991) is testament to an ethos of sustainability, resilience and tenacity evidenced in some corners of the sectors. Additionally, although large scale heritage initiatives may require substantive capital, smaller investments (either internal to the university or external) may yield significant results. As exhibited in other areas of the heritage sector, a little funding may go a long way, and even further when costs may be borne out within a cross-industry collaboration (Bewley and Maeer 2014; Clark 2006; Clark and Maeer 2008; Dubuc 2011).

The NBHASC has leveraged its value and identity against the vibrancy of the local and regional sports heritage groups and academic sport history networks. Strategically, in addition to facilitating community engagement, NBHASC has a commitment to scholarly activity. In doing so NBHASC has positioned itself as able to contribute to supporting and strengthening the university's research profile. Similarly, in keeping with the university's agendas and to maximise engagement, NBHASC has also made developing undergraduate and post-graduate teaching and student work placement opportunities a priority. Articulating the development of the NBHASC in this paper is, thus, of value in demonstrating the possibilities and constraints of university's engagement in heritage making. Moreover, the NBHASC (and issues therein) add weight to wider debates and calls for greater network 
formation and collective advocacy to improve the wider (sport) heritage industry's sustainability.

\section{Conclusion}

The intention of this paper was to underscore how university alignment can be a doubleedge sword for heritage projects. On the one side, there is apparent harmony of intention and ideology as co-contributors to the progression of the Humanities. Working together, the Tertiary and Culture and Arts sectors are, for example, well positioned to make a stronger case for heritage processes and outcomes. On the other, intersectionality may not be enough of a buffer against forces of austerity and antagonistic political climates that have shown hostility to both the Tertiary and Culture and Arts sectors (Benneworth and Jongbloed 2010; Giroux 2014; Janes 2009). Partnership may also require an acknowledgement of the fragility of the relationship and necessitate considerable faith and trust. Yet as scholars remind us (e.g. Reilly, 2015; Reilly, Clayton and Hughson 2014; Krüger 2014), and what the case of the NBHASC makes clear, is that although inter/cross-sectional action may be fraught with uncertainty, it may present a better alternative than university and heritage sectors attempting to go it alone in their respective initiatives.

Independent work and existence, Krüger (2014) notes, is a difficult option. As such, there needs to be more effort (particularly by universities) to traverse intersectional spaces. With respect to sport heritage archives, Krüger (2014) argues for the need to better support nonprofit, local and club archives, their management and sustainability; part of which entails aiding collection and mapping exercises, advocating the utility of network formation, collaborating on sustainability measures and facilitating cross-sector dialogue. Similarly, Deom (2008) suggests academia and culture and arts sectors could share expertise, professional advice, and/or training and development opportunities, which might develop workers' competencies to better meet constituents' needs. Collaborations might also be orientated around construction of courses, modules, programmes (Dubuc 2011) and research assistantships (Deom 2008) that might attract student interest (and add financial weight and stronger 'impact' rationale in furthering the case for academic and external funding and infrastructure support). Here, in the efforts to consolidate stronger foundations for the NBHASC (and other similar ventures), it is also useful to rehearse Pinson's (2017) calls to leverage and position heritage activities as collective territorial resources that have distinct, definable and indefinite value not only to specific communities (e.g. national basketball fanatics), but also to the wider cultural and social landscape of the territories they inhabit. In this way basketball heritage could be framed as a broader narrative about the United Kingdom's modernisation, cross-cultural identity and its affectations for sport and leisure therein. In keeping with disciplinary and sector trends, the area of digitisation, digital heritage management, and virtual public engagement development may provide another theme for collaborative endeavours (Kalay, Kvan and Affleck 2008; Parry 2010). Notwithstanding uncertainties, the suggestions here hold possibilities for those working at the nexus of academia and heritage spaces. The challenge now is to explore how fertile intersectional opportunities might be effectively maintained irrespective of contextual perturbations. 


\section{References}

Ahmed, Y. 2006. "The scope and definitions of heritage: From tangible to intangible." International Journal of Heritage Studies, 12 (3): 292-300.

Benneworth, P. and Jongbloed, B. W. 2010. "Who matters to universities? A stakeholder perspective on humanities, arts and social sciences valorisation." Higher Education, 59 (5): 567-588.

Bewley, R. and Maeer, G. 2014. "Heritage and economy: Perspectives from recent heritage lottery fund research." Journal of Public Archaeology, 13 (1-3): 240-249.

Boys, J., Boddington, A. and Speight, C., eds. 2016. Museums and Higher Education Working Together: Challenges and Opportunities. London: Routledge.

Booth, D. 2012. Bondi Park: Making, practicing and performing a museum. In Phillips, M. (Ed.) Representing the Sporting Past in Museums and Halls of Fame. New York: Routledge, 204-230.

Borish, L. J. and Phillips, M. G. 2012. "Sport history as modes of expression: Material culture and cultural spaces in sport and history." Rethinking History, 16 (4): 465-477.

Bouchier, N. B. and Cruickshank, K. 1998. "Reflections of creating critical sport history for a popular audience: The people and the bay." Journal of Sport History, 25 (2): 309-316.

Brittain, I., Ramshaw, G. and Gammon, S. 2013. "The marginalisation of Paralympic heritage." International Journal of Heritage Studies, 19 (2): 171-185.

Brown, R. and Carasso, H. 2013. Everything for sale?: the marketisation of UK higher education. London: Routledge.

Clark, K. and Maeer, G. 2008. "The cultural value of heritage: Evidence form the Heritage lottery fund." Journal of Cultural Trends, 17 (1): 23-56.

Clark, K., ed. 2006. Capturing the public value of heritage: The proceedings of the London conference. London: English Heritage.

Crawford, S. 1996. "The New Zealand Rugby Museum." Journal of Sport History, 23 (3): 338340.

Day, D., Carter, N. and Carpenter, T. 2013. "The Olympics, amateurism and Britain' coaching heritage." International Journal of Heritage Studies, 19 (2): 139-152.

Déom, C. 2008. "Partners in Preservation: University of Montreal Research for the Preservation of the Montreal School Board Historic Schools." International Journal of Heritage Studies, 14 (6): 573-588.

Dubuc, É. 2011. "Museum and university mutations: the relationship between museum practices and museum studies in the era of interdisciplinarity, professionalisation, globalisation and new technologies." Museum Management and Curatorship, 26 (5): 497-508.

Fairley, S. and Gammon, S. 2005. "Something lived, something learned: Nostalgia's expanding role in sport tourism." Sport in Society, 8 (2): 182-197. 
Faulkner, C. 2017. Shooting from beyond the arc: An examination of Basketball player's migratory experiences, Unpublished Ph.D. Thesis (University of Worcester).

Falcous, M. and Maguire, J. 2005. "Globetrotters and local heroes? Labor migration, basketball, and local identities." Sociology of Sport Journal, 22 (2): 137-157.

Friedman, M. 2007. "The spectacle of the past: Leveraging history in Fenway Park and Camden Yards." In Gammon, S. \& Ramshaw, G. (Eds.) Heritage, Sport and Tourism: Sporting Pasts - Tourist Futures. London: Routledge, 103-122.

Gammon, S. and Ramshaw, G. (Eds.). 2007. Heritage, Sport and Tourism: Sporting Pasts Tourist Futures. London: Routledge.

Giroux, H. 2014. Neoliberalism's war on higher education. Chicago: Haymarket Books.

Hardy, S, Loy, J. and Booth, D. 2009. "The material culture of sport: Toward a typology." Journal of Sport History 36 (1): 129-152.

Harvey, D.C. 2001. "Heritage pasts and heritage presents: Temporality, meaning and the scope of heritage studies." International Journal of Heritage Studies 7 (4): 319-338.

Haxthausen, C. W. 2001. The two art histories: The museum and the university. Williamstown, MA: Sterling and Francine Clark Art Institute.

Higher Education Statistics Authority (2017) https://www.hesa.ac.uk/data-and-analysis. (Accessed 13 November 2016).

Hill, J., Moore, K. and Wood., J. 2012. Sport, history, and heritage: Studies in public representation. Woodbridge: Boydell Press.

Huggins, M. 2012. "Gone, but not forgotten: Sporting heroes, heritage and graveyard commemoration." Rethinking History, 16 (4): 479-495.

Janes, R. R. 2009. Museums in a troubled world: Renewal, irrelevance or collapse? London: Routledge.

Johnes, M. 2013. "Sport, History, and Heritage, Studies in Public Representation (Book review)." The International Journal of the History of Sport, 30 (17): 2119-2121.

Johnes, M. and Mason, R. 2003. "Soccer, public history and the National Football Museum." Sport in History, 23 (1): 115-131.

Kalay, Y. E., Kvan, T. and Affleck, J. 2008. New Heritage: New Media and Cultural Heritage. London: Routledge.

Kidd, B. 1996. "The Making of a Hockey Artefact; A Review of the Hockey Hall of Fame." Journal of Sports History, 23 (3): 328-334.

Kiuri, M. and Teller, J. 2015. "Olympic Stadiums and Cultural Heritage: On the Nature and Status of Heritage Values in Large Sport Facilities." The International Journal of the History of Sport, 32 (5): 684-707.

Kohe, G. 2010. "The New Zealand Sports Hall of Fame: Civic representations of sporting and olympic history." Sport in Society, 13 (10): 1498-1515. 
Krüger, M. 2014. "Historiography, Cultures of Remembrance and Tradition in German Sport. The International Journal of the History of Sport." 31 (12): 1425-1443.

Maguire, J. 1994. "American Labour Migrants, Globalization and the Making of English Basketball." In: J. Bale and Maguire, J., eds. The Global Sports Arena: Athletics Talent Migration in an Interdependent World. London: Frank Cass, 226-255.

Mandel, J. 2015. 'The arrival of basketball in England revisited.' Unpublished M.A thesis (De Montfort University).

Mason, R. 2006. "Cultural theory and museum studies." In: A companion to museum studies. S. Macdonald, ed. Oxford: Blackwell, 17-32.

McCall, V. and Gray, C. 2014. "Museums and the 'new museology: theory, practice and organisational change." Journal of Museum Management and Curatorship, 29 (1): 19-35.

Moore, K. 2013. "Sport History, Public History, and Popular Culture: A Growing Engagement." Journal of Sport History, 40 (1): 401-417.

Moore, K. 1997. Museums \& Popular Culture. London: Leicester University Press.

Myerscough, K. 1993. The Development of Basketball in England \& the USA: The Contribution of the YMCA Movement, Unpublished M.A. Thesis (Manchester University).

Mydland, L. and Grahn, W. 2012. "Identifying heritage values in local communities." International Journal of Heritage Studies, 18 (6): 564-587.

Osmond, G. and Phillips, M. G. 2011. "Enveloping the past: Sport stamps, visuality and museums." International Journal of the History of Sport, 28 (8-9): 1138-1155.

Paradeise, C., Reale, E., Bleiklie, I. and Ferlie, E., Eds. 2009. University governance. Springer Netherlands.

Parry, R, ed. 2010. Museums in Digital Age. London: Routledge.

Pfleegor, A. G. and Seifried, C. S. 2012. "Is building new the only option? A teaching approach to heritage management." Sport Management Education Journal, 6 (1): 32-42.

Phillips, M.G. 2008. Public history and sport history: Evaluating commissioned histories and historical documentaries. Journal of Sport History, 35 (3): 383-410.

Phillips, M., ed. 2012. Representing the Sporting Past in Museums and Halls of Fame. New York: Routledge.

Phillips, M.G. and Tinning, R. 2011. "Not just 'a book on the wall': Pedagogical work, museums and representing the sporting past." Sport, Education and Society, 16 (1): 55-69.

Pinson, J. 2017. "Heritage sporting event: Theoretical development and configurations." Sport \& Tourism, 21 (2): 133-152.

Reilly, J.N. 2014. 'Sport, Museums and Cultural Policy.' Unpublished doctoral thesis. University of Central Lancashire 
Reilly, J. 2015. "The Development of Sport in Museums." The International Journal of the History of Sport, DOI: 10.1080/09523367.2015.1108306

Reilly, J., Clayton, J. and Hughson, J. 2014. "Uniting sport and heritage: An evaluation of the Our Sporting Life exhibition programme." Cultural Trends, 23 (1): 42-55

Research Excellence Framework (2014) http://results.ref.ac.uk/Results/BySubmission/660 (Accessed 10 December 2016).

Riddell, S., Weedon, E. and Minty, S., eds. 2015. Higher Education in Scotland and the UK. Edinburgh: Edinburgh University Press.

Ritchie, B.W. and Adair, D. (2004) "Sport Tourism: An introduction and overview." In Ritchie, B. W. \& Adair, D. (Eds.) Sport Tourism: Interrelationships, Impacts and Issues. Toronto: Channel View Publications, 1-9.

Robertson, I. 2016. Heritage from below. Abingdon, Oxon: Routledge.

Sheen, T. 2016. 'Team GB funding cuts are killing British basketball', The Independent, http://www.independent.co.uk/sport/us-sport/national-basketball-association/team-gbfunding-cuts-are-killing-british-basketball-a6886486.html (Accessed 16 August 2016).

Smith, L. 2006. Uses of Heritage. London: Routledge.

Snyder, E.E. 1991. "Sociology of Nostalgia: Sport Halls of Fame and Museums in America." Sociology of Sport Journal (8): 228-238.

Stride, C., Wilson, J. P. and Thomas, F. 2013. "Honouring heroes by branding in bronze: Theorizing the UK's football statuary." Sport in Society, 16 (6): 749-771.

Teather, L. 1991. "Museum studies: Reflecting on reflexive practice." Museum management and curatorship 10, 403-417.

University of Worcester (2013) Strategic Plan 2013-2018, Worcester: University of Worcester, http://www.worcester.ac.uk/documents/university-worcester-strat-plan-201318.pdf (Accessed 20 December 2017).

Vamplew, W. 1998. "Facts and Artefacts: Sports Historians and Sports Museums." Journal of Sport History, 25 (2): 268-282.

Vamplew, W. 2004. "Taking a Gamble or a Racing Certainty: Sports, Museums and Public Sports History." Journal of Sport History, 31 (2): 178.

Waterton, E. and Watson, S. 2015. The Palgrave handbook of contemporary heritage research. Basingstoke: Palgrave.

Watson, D. 2002. "Can we all do it all? Tensions in the mission and structure of UK higher education." Higher Education Quarterly, 56 (2): 143-155.

Wood, J. 2005. "Olympic Opportunity: Realising the Value of Sport Heritage for Tourism in the UK." Journal of Sport Tourism, 10 (4): 307-21. 
